\title{
Inovações tecnológicas e organizacionais em escritórios e os impactos na qualidade de vida no trabalho'
}

\author{
Romildo Garcia Brusiquese ${ }^{2}$ e Mário César Ferreira ${ }^{3}$ \\ Universidade de Brasília (Brasília, DF)
}

\begin{abstract}
Este estudo buscou identificar as novas exigências do trabalho em escritórios, no atual cenário produtivo, motivadas pelas inovações tecnológicas e organizacionais e sua repercussão na qualidade de vida no trabalho. O referencial teórico fundamentou-se nos pressupostos da Ergonomia da Atividade, e o método baseou-se na Análise Ergonômica do Trabalho (AET). A pesquisa, de abordagem qualitativa, utilizou entrevistas semiestruturadas individuais, com a participação de trinta profissionais de uma instituição financeira brasileira de grande porte, e os dados foram analisados com o uso do programa Alceste. Os resultados apontaram que os entrevistados reconhecem a importância das inovações tecnológicas na realização de suas atividades, mas associam a elas o advento de novas exigências, decorrentes principalmente da intensificação e da maior complexidade e controle do trabalho, que resultam no aumento do custo humano do trabalho.
\end{abstract}

Palavras-chave: Inovações tecnológicas, Novas exigências, Qualidade de vida no trabalho, Ergonomia da atividade.

Technological and organizational innovations in offices and the impacts on the quality of work life

This study aimed to identify the new requirements of work in offices, in the current production scenario, driven by technological and organizational innovations, and their impact on the quality of work life. The theoretical framework was based on the assumptions of Ergonomics of Activity, and the method was based on Ergonomic Work Analysis (EWA). The research, which has a qualitative approach, used individual semi-structured interviews, with the participation of thirty professionals from a large Brazilian financial institution, and the data were analyzed using the software Alceste. The results indicated that respondents recognize the importance of technological innovations to carry out their activities, but they associate to them the advent of new requirements, mainly due to the intensification and greater complexity and control of work, resulting in an increased human cost of work.

Keywords: Technological innovations, New requirements, Quality of work life, Ergonomics of activity.

\section{Introdução}

$\mathrm{O}$ efeitos da globalização têm provocado considerável impacto na vida dos trabalhadores e a transformação do trabalho decorrentes da introdução de novas tecnologias e dos consequentes ajustes organizacionais no ambiente de produção, tem sido apontada em diversas pesquisas. Ferreira (2009) caracteriza essas transformações como metamorfoses do trabalho contemporâneo e chama a atenção para suas consequências nas atividades dos trabalhadores. Friedmann (1952) já apontava que, em um cenário de profundas transformações, oriundas das mudanças tecnológicas, esperava-se também uma transformação de ordem emocional e mental nas formas de sentir, pensar e agir de grande parte das pessoas.

1 Trabalho baseado na Dissertação de Mestrado intitulada Inovações tecnológicas e organizacionais e a influência das novas exigências do trabalho em escritórios na qualidade de vida no trabalho, defendida no ano de 2009, no Instituto de Psicologia da Universidade de Brasília.

2 Mestrado e doutorado em andamento em Psicologia Social, do Trabalho e das Organizações/Ergonomia pela Universidade de Brasília.

3 Pós-Doutorado em Ergonomia da Atividade Aplicada à Qualidade de Vida no Trabalho pela Université Paris 1 Sorbonne (França). 
Diversos autores compartilham o pressuposto de que fatores ligados à competitividade constituem elemento propulsor de iniciativas envolvendo a introdução de mudanças com base na tecnologia, de forma a tornar o trabalho mais produtivo. Kaplan e Norton (1996) reforçam que as empresas estão em meio a uma transformação revolucionária na qual a competição da era industrial cede lugar à competição da era da informação, cujo ambiente, em especial no setor de serviços, requer novas capacidades e diferenciais para o sucesso competitivo.

No cenário atual, em que se multiplicam discursos e ações no sentido de se buscar a automatização de processos e a racionalização do trabalho, liberando o ser humano para atividades como planejar e gerir, percebe-se a existência de modelos produtivos fortemente apoiados nas bases mecanicistas do início do século passado. Nesse sentido, alguns autores, como Abrahão e Pinho (2002), apontam que as transformações nas situações de trabalho, em decorrência da informatização, revolucionam as estruturas temporais e espaciais de produção, bem como seu conteúdo e sua organização, mas salientam que as evoluções tecnológicas, que se constituiriam como espaço importante para a melhoria das condições de trabalho, sustentam-se sobre as bases do taylorismo.

Dado o quadro exposto, o objetivo geral do trabalho de pesquisa ora relatado foi identificar as novas exigências do trabalho em escritórios, motivadas pelas inovações tecnológicas e organizacionais e sua repercussão na qualidade de vida no trabalho.

As questões de pesquisa (Q), elaboradas com base nos objetivos específicos, bem como suas correspondentes hipóteses $(\mathrm{H})$, são apresentadas a seguir:

- Q: Como os trabalhadores percebem as inovações tecnológicas e organizacionais no seu trabalho?

- H: Os trabalhadores percebem as inovações como algo necessário, que provê condições de racionalizar sua atividade, mas que demanda empenho adicional no trabalho.

- Q: Como se caracterizam as novas exigências do trabalho, acarretadas pelas inovações tecnológicas e organizacionais, na visão dos trabalhadores?

- H: As novas exigências são entendidas como fatores associados às inovações tecnológicas, que demandam grande conjunto de esforços cognitivos, com possibilidades de repercussão no aspecto físico dos trabalhadores.

- Q: Quais são as formas pelas quais as inovações interferem na implementação de estratégias operatórias pelos trabalhadores, quando buscam a eficiência com preservação de sua segurança e saúde?

- H: As inovações, concebidas sem a participação dos usuários, tornam mais complexas suas ações no trabalho e limitam o desenvolvimento de estratégias operatórias na realização de suas atividades.

- Q: Quais são os efeitos das novas exigências do trabalho na qualidade de vida no trabalho, percebidos pelos trabalhadores?

- H: As novas exigências do trabalho têm o potencial de interferir negativamente na eficiência e na saúde dos trabalhadores, comprometendo sua qualidade de vida no trabalho.

\section{Quadro teórico de referência de análise do objeto de pesquisa}

As dimensões analíticas que estruturaram a condução do projeto de pesquisa, os aspectos mais relevantes da revisão da literatura e as categorias conceituais adotadas são 
apresentados a seguir. Tendo o enfoque da Ergonomia da Atividade como fonte de inspiração teórica, explicitamos alguns de seus principais traços neste tópico.

\section{Inovações tecnológicas e organizacionais e novas exigências do trabalho}

$\mathrm{Na}$ busca por uma redefinição do papel da tecnologia da informação, em especial no seu viés social, Egbu e Botterill (2002) argumentam que esse recurso não se refere apenas a computadores, bancos de dados e repositórios de informações, mas defendem que o tema poderia ser entendido menos pela sua capacidade de armazenar informações explícitas e mais pelo seu potencial de comunicação e cooperação entre pessoas.

Em referência à dinâmica nos processos de inovação da tecnologia digital e às dificuldades de sua compatibilização com as necessidades dos usuários, Howell (1993) salienta que um componente de software ou hardware caminha para a obsolescência a partir do momento em que é incorporado ao sistema operacional. Nesse sentido, Nathanael, Marmaras e Papantoniou (2003) e Olson e Olson (2003) observam que a cada nova aplicação que surge, em substituição ou aprimoramento da anterior, surgem novos desafios no campo da interação homem-computador.

Segundo Van de Ven (1986), as inovações não são apenas adaptadas a arranjos produtivos, mas também transformam estruturas e práticas desses ambientes. De acordo com a Society for Human Resource Management (2007), nos últimos anos têm sido vistos uma expansão e um incremento sem precedentes na comunicação on-line; novos softwares estão pressionando as fronteiras da comunicação no trabalho para além do e-mail rumo às tecnologias colaborativas, que denomina mídias sociais (programas on-line que permitem às pessoas interagir, colaborar, trocar informação e publicar conteúdos na internet de uma maneira simples e amigável ao usuário, como blogs e podcastings).

Nathanael e Marmaras (2001), ao inserir na discussão o elemento interface entre o usuário e o dispositivo técnico, apontam que a abordagem tradicional da interação homemcomputador tem focado a otimização desse contato sem se considerar o contexto no qual ocorre a utilização do equipamento.

A introdução de inovações tecnológicas no contexto produtivo leva, inevitavelmente, à adoção de novas maneiras de organizar o trabalho como forma de compatibilizar o aporte de recursos técnicos com suas possibilidades de uso e, assim, chegar aos objetivos esperados. Nesse contexto, Howell (1993) atenta para a paradoxal situação em que máquinas, que podem fazer mais e mais rápido, estabelecem as bases para sistemas que acabam por intensificar as demandas de ordem cognitiva aos usuários.

Ao abordar o perfil do novo trabalhador, Ferreira (2006a) destaca a autonomia (relativa e vigiada), a autodisciplina (prontidão mental normativa), o comprometimento organizacional (foco nos objetivos) e a criatividade (modulada na lucratividade), dentre outras características. Nesse sentido, Marmaras e Pavard (1999) apontam que a análise do trabalho em ambiente de tecnologia revela a existência de tarefas cognitivas de grande complexidade e com potencial limitador à ação dos usuários. Segundo os autores, essas limitações envolvem: a) objetivos diversos e critérios de competitividade a ser alcançados; b) grande quantidade de objetos a ser monitorados e controlados; c) insuficiente ou excessiva quantidade de informação a ser tratada; d) operações mentais em grande quantidade ou de muita complexidade; e e) pouca disponibilidade de tempo para o desempenho dessas operações.

Tratando a questão do fluxo de informações, Olson e Olson (2003) destacam que a facilidade na comunicação via mensagens eletrônicas (e-mails) tem produzido uma sobrecarga de informações. Bellotti, Ducheneaut, Howard, Neuwirth e Smith (2002), em estudo realizado com empresas adeptas do e-mail, observaram que, quando os usuários não estavam lendo ou 
enviando mensagens, geralmente estavam trabalhando em objetos trocados por esse dispositivo, enviados como anexos, e que a administração desse fluxo de mensagens constituía considerável sobrecarga de trabalho.

Em análise de pesquisa realizada na França, no ano de 2007, sobre a opinião dos trabalhadores franceses a respeito das novas exigências do trabalho, Ferreira (2008b) aponta que as características das novas exigências do trabalho estão associadas ao aumento do ritmo de trabalho, da autonomia, do exercício da polivalência e à responsabilização individual na tomada de decisão. Os resultados desta pesquisa mostram que os trabalhadores franceses não são "alérgicos" às inovações tecnológicas, mas salientam enfaticamente a importância de sua participação no processo de reconversão tecnológica.

\section{Dimensões analíticas: delimitação}

Os conceitos elaborados para as dimensões analíticas estudadas na pesquisa foram:

- Inovações tecnológicas: ações de incremento de recursos técnicos, como instrumentos e equipamentos eletrônicos, de comunicação e de informática (hardware), programas de computador (software) e sistemas de informação conectados em rede local ou pela internet, necessários à viabilização de uma atividade produtiva.

- Inovações organizacionais: conjunto de transformações no ambiente produtivo, relacionadas à forma de prescrição, operacionalização e gestão do trabalho, em decorrência da introdução de inovações tecnológicas.

- Novas exigências do trabalho: conjunto de demandas ao trabalhador, manifestadas por transformações decorrentes da introdução de inovações tecnológicas e organizacionais, que se caracterizam pela intensificação dos esforços físicos, cognitivos e afetivos e que têm o potencial de gerar consequências prejudiciais à segurança, à saúde, ao bem-estar, à eficiência e à qualidade de vida no trabalho.

\section{Qualidade de vida no trabalho}

Os relatos de estudos com abordagem na temática qualidade de vida no trabalho (QVT) trazem, não raramente, menções à dificuldade na obtenção de consenso no que se refere à definição de seu conceito. Royuela, López-Tamayo e Suriñach (2007, p. 4) apontam que a European Commission assume que "não há padrão ou definição acordada de qualidade de vida no trabalho na academia nem na literatura especializada". Nas palavras de May, Lau e Johnson (1999), o tema QVT tem sido reconhecido como um construto multidimensional e não pode ser universal ou eterno, e acrescentam que os objetivos básicos de um efetivo programa de QVT são o incremento das condições de trabalho, na perspectiva dos trabalhadores, e melhor efetividade organizacional, na perspectiva do empregador.

Mendes e Ferreira (2004), citados por Ferreira (2006b), apresentam uma abordagem de natureza preventiva sobre a QVT. O foco central consiste na remoção dos fatores causadores de mal-estar no trabalho. Nesse sentido, a QVT passa a ser uma tarefa compartilhada por todos e não apenas sob responsabilidade do indivíduo - e passa a consistir em uma busca permanente de harmonia entre o bem-estar, a eficiência e a eficácia no trabalho, não restringindo sua atenção à produtividade.

\section{Ergonomia da Atividade: traços característicos}

Grandjean (1998) aponta que o desenvolvimento da tecnologia também influenciou a Ergonomia. Sob essa perspectiva, observando o caráter dinâmico necessário ao 
desenvolvimento da disciplina, Laville (1977, p. 10) aponta que "a Ergonomia liga-se simultaneamente ao progresso dos conhecimentos científicos e à evolução dos problemas do trabalho", enquanto Daniellou $(2004$, p. 6), atendo-se à questão dos interesses produtivo e social, ressalta que "a Ergonomia leva em conta, classicamente, um duplo critério: o de saúde dos trabalhadores e o de eficácia econômica".

O referencial teórico no qual se inspirou a pesquisa foi a Ergonomia da Atividade, que, segundo Ferreira e Mendes (2003), refere-se à abordagem científica que investiga a relação entre os indivíduos e o contexto de produção; e seu objetivo principal consiste em compreender os indicadores críticos presentes nesse contexto, para transformá-los com base em uma solução de compromisso que atenda às necessidades e aos objetivos de trabalhadores, gestores, usuários e consumidores.

Parte considerável dos fatores responsáveis por inadequações nas situações de trabalho encontra-se no universo entre a concepção (trabalho prescrito) e a utilização (trabalho real) de soluções disponibilizadas para a realização das atividades. Segundo Guérin, Laville, Daniellou, Duraffourg e Kerguelen (2001, p. 14), "as condições determinadas não são as condições reais, e o resultado antecipado não é o resultado efetivo. Essa é uma primeira razão pela qual a tarefa não deve ser confundida com o trabalho".

O chamado tecnocentrismo é percebido em diversas situações, como no desenho de sistemas na área de tecnologia da informação, os quais são guiados mais por modelos teóricos, formais e por técnicas de domínio de aplicações do que por problemas reais e dificuldades defrontados pelos usuários (Marmaras \& Pavard, 1999). Essa situação pode ser exemplificada pela observação de Ferreira (2004), que aponta a existência de modelos de automatização de tarefas com a criação de novos aplicativos cujas denominações se baseiam nos vocabulários dos programadores, produzindo inúmeros limites de usabilidade.

Segundo Ferreira e Mendes (2003), o custo humano do trabalho expressa o dispêndio dos trabalhadores nas esferas física, cognitiva e afetiva diante das contradições existentes no contexto de produção. Segundo os autores, o custo humano do trabalho mantém estreita relação com a atividade, é caracterizado pela imposição externa sob a forma de constrangimentos às atividades dos trabalhadores e é gerido por meio de estratégias de mediação individual e coletiva, podendo assumir formas de confrontações positivas ou negativas que impactam a dinâmica das vivências de bem-estar e mal-estar no trabalho.

\section{Abordagem metodológica}

Para a realização da pesquisa, optou-se por estudo de caso com utilização de método que se baseou nos pressupostos da Análise Ergonômica do Trabalho, de acordo com Ferreira (2003), Guérin et al. (2001), Iida (2005) e Wisner (1994a). O estudo adotou uma abordagem qualitativa de pesquisa e, para o tratamento dos dados, foi utilizado o programa Alceste ${ }^{4}$.

\section{Análise Ergonômica do Trabalho}

A Análise Ergonômica do Trabalho (AET) visa a aplicar os conhecimentos da Ergonomia para analisar, diagnosticar e corrigir uma situação real de trabalho (Iida, 2005). Constitui-se, também, como objetivo da AET, independentemente da necessidade de atuações de ordem corretiva, o aprimoramento do trabalho. Com base em Ferreira (2003), Guérin et al.

4 Alceste (Analyse Lexicale par Contexte d'un Ensemble de Segments de Texte): ferramenta desenvolvida por Max Reinert para investigar a distribuição de vocabulário em textos escritos ou transcritos, segundo Bauer e Gaskell (2002). 
(2001), Iida (2005) e Wisner (1994a), a AET pode ser estruturada nas etapas de análise da demanda, da tarefa, da atividade e do ambiente, seguidas de diagnóstico e de recomendações.

Como destacam Guérin et al. (2001, p. 26): "A atividade de trabalho é o elemento central que organiza e estrutura os componentes da situação de trabalho. É uma resposta aos constrangimentos determinados exteriormente ao trabalhador e, ao mesmo tempo, é capaz de transformá-los".

\section{Caracterização da organização pesquisada}

O contexto de trabalho objeto da pesquisa localizava-se em diretoria com foco em responsabilidade socioambiental de uma instituição financeira brasileira de grande porte, inserida em ambiente marcado por alta competitividade e caracterizada pelo forte aporte tecnológico, tanto em seus processos internos como na estrutura de atendimento a clientes e usuários.

\section{Critérios de seleção e perfil dos participantes}

Dado o fato de que a situação de trabalho analisada se mostrou aplicável a todos os funcionários do contexto estudado, fazendo de todos potenciais participantes da pesquisa, foram selecionados trinta participantes, todos ocupantes de cargos técnicos ou de assessoria.

O profissional participante do estudo utiliza, em suas atividades, estação de trabalho em ambiente compartilhado com outros profissionais e recursos tecnológicos como aparelho telefônico e computador conectado à internet e rede local, entre outros. O controle de início e final de expediente, assim como do intervalo de almoço, é efetuado por meio de sistema de ponto eletrônico mediante registro individual, pelos funcionários, nos computadores da instituição.

A situação de trabalho na qual se insere esse perfil de trabalhador assemelhou-se, sob a ótica deste estudo, a uma espécie de commodity laborativa, presente em qualquer cenário produtivo em ambientes de escritórios informatizados, como seguradoras, escritórios de advocacia, de contabilidade, entre outros, independentemente do país de localização, haja vista os efeitos da globalização.

Os dados mostram equilíbrio na proporção entre homens e mulheres; $57 \%$ eram casados; havia prevalência de funcionários com mais de 30 anos de idade (73\%); e alto percentual com formação de nível superior (83\%). A maioria (81\%) ocupava comissão de Assessor Pleno ou Sênior; 54\% tinham menos de dois anos na área de atuação; e 60\% tinham entre 21 e 30 anos de vínculo empregatício com a instituição.

\section{Descrição dos instrumentos}

Os instrumentos utilizados como suporte aos trabalhos de coleta de dados foram: a) gravadores digitais de áudio; b) tópico guia (roteiro de apoio às entrevistas, de acordo com Bauer e Gaskell [2002]); e c) termos de compromisso e de consentimento ${ }^{5}$.

\footnotetext{
5 Mediante uso dos documentos Termo de Compromisso e Termo de Consentimento, assinados pelo pesquisador, por representante da organização pesquisada e pelos participantes, foram reafirmados, formalmente, os princípios éticos da pesquisa. Dos referidos documentos constaram solicitações de autorização para a realização da pesquisa e publicação dos resultados, e manifestação formal assegurando a preservação do anonimato da instituição pesquisada e dos entrevistados.
} 


\section{Procedimentos}

A coleta de dados ocorreu no período de 12/01/2009 a 13/03/2009 e consistiu de entrevistas individuais semiestruturadas, com duração média de 44 minutos, com apresentação das seguintes questões, no início da abordagem aos temas: a) Você considera que, nos últimos anos, houve no seu ambiente de trabalho um incremento de recursos técnicos voltados para a realização das tarefas? b) Como se caracterizou tal incremento de recursos técnicos? e c) Quais foram os efeitos desse processo de inovações tecnológicas e organizacionais?

Após a realização das entrevistas, procedeu-se às transcrições literais das verbalizações gravadas, com vistas à construção de um corpus único, compatível com as condições estabelecidas pelo programa Alceste.

\section{Resultados, análise e discussão}

Após o tratamento do corpus, o Alceste apresentou a identificação de classes de palavras, denominadas núcleos temáticos estruturadores (NTEs). Nos quadros que seguem, são apresentadas as unidades de contexto elementar (UCEs) de cada núcleo, que retratam as verbalizações dos entrevistados.

O Quadro 1 apresenta UCEs relacionadas ao NTE Intensificação do trabalho.

\section{Quadro 1: NTE Intensificação do trabalho}

\begin{tabular}{|c|c|}
\hline Sequência & UCEs \\
\hline 1. & $\begin{array}{l}\text { “... quando você tem instrumentos... softwares sofisticados... então o grau de complexidade, de } \\
\text { exigência, ele aumenta muito" }\end{array}$ \\
\hline 2. & $\begin{array}{l}\text { "... a informação chega muito rápido, e a resposta tem que ser mais rápida ainda, só que as respostas } \\
\text { têm exigências de qualidade, de sigilo, de precisão" }\end{array}$ \\
\hline 3. & $\begin{array}{l}\text { "... pode ser aumentada a quantidade de metas, então, isso vem junto, sim; é uma resposta a essa } \\
\text { nova era da tecnologia; você tem que render mais para ocupar melhor o tempo" }\end{array}$ \\
\hline 4. & $\begin{array}{l}\text { "... na mesma medida que eu sou exigido mais, ou seja, eu tenho que produzir mais, eu tenho que } \\
\text { arranjar tempo pra aquilo" }\end{array}$ \\
\hline 5. & $\begin{array}{l}\text { "... aumentou a quantidade de informações como a qualidade e como a exigência de retorno, porque } \\
\text { você tem mais informação..." }\end{array}$ \\
\hline 6. & “... porque as informações eram proporcionais ao seu tempo e agora, não" \\
\hline 7. & “... agiliza, mas, ao mesmo tempo, você tem milhões de ações a realizar" \\
\hline
\end{tabular}

Os relatos prevalecentes do grupo de UCEs desse núcleo deixam clara a preocupação dos entrevistados com os fatores relacionados a seguir, que, na sua percepção, vieram junto com as inovações tecnológicas e organizacionais.

- Intensificação do trabalho: o fenômeno, na visão dos entrevistados, ocorre em função do aumento da quantidade de atividades, da velocidade com que chegam as demandas e da redução do tempo disponível para seu atendimento. Esses aspectos da intensificação do trabalho sob a influência de inovações tecnológicas e organizacionais foram verificados nas abordagens de Ferreira (2008b); Howell (1993); Marmaras e Pavard (1999); McCampbell, Clare e Gitters (1999) e Wisner (1994b). 
- Aumento da complexidade das tarefas: essa percepção dos entrevistados foi encontrada nos argumentos de Antunes (2007); Howell (1993); McCampbell et al. (1999); e Queiroz (2003). A complexidade das tarefas sob a influência do trabalho informatizado também é encontrada na abordagem de Abrahão e Pinho (2002), que apontam como seu fruto a "intelectualização" do trabalho.

- Maior rigor no nível de atributos exigidos do produto do trabalho: esse elemento, identificado nas verbalizações, foi encontrado na abordagem de Antunes (1995), citada por Peduzzi (2002), que o associa às exigências mais individualizadas do mercado, e de Ferreira (2008b), que destaca normas de produção e metas rigorosas presentes na realidade dos trabalhadores.

- Aparato de pressão e controle para verificação do cumprimento de metas: a referência, pelos entrevistados, a esse maior controle e vigilância sobre as atividades dos indivíduos, como o registro e o armazenamento de informações que evidenciam as decisões e os procedimentos adotados pelos trabalhadores, foi verificada nas análises de Ferreira (2009); Leite (1990), citado por Leite (1994), e Weick (2001) e Zuboff (1988), citados por Queiroz (2003). Ações de monitoração excessiva de desempenho podem interferir nas relações sociais de trabalho, em especial entre chefias e subordinados, e provocar impactos negativos nos resultados da organização e na saúde dos trabalhadores.

O relato dos entrevistados evidencia questionamento a respeito do efetivo ganho advindo das inovações tecnológicas e organizacionais. Os discursos mostraram o reconhecimento de avanços no aprimoramento das ferramentas, com reflexos positivos na produtividade, mas não se percebeu sentimento análogo em relação à diminuição do custo humano do trabalho, deixando transparecer que o ganho em evolução tecnológica é compensado pelo adensamento do trabalho, com resultado nulo em termos de melhoria da qualidade de vida no trabalho.

Essa visão encontra amparo em abordagens da literatura revisada, onde os autores colocam em questão os reais efeitos das inovações, como Dal Rosso (2008), que indaga se a qualidade de vida é favorecida ou as exigências de esforços ao trabalhador é que são aumentadas, e Ho (1997), que destaca não apenas a eficiência e a redução da concentração do trabalho como resultado do aporte tecnológico, mas, também, a criação de vários fatores geradores de estresse, como pressão, sobrecarga e insegurança no trabalho.

O Quadro 2 apresenta UCEs relacionadas ao NTE Organização do trabalho.

\section{Quadro 2: NTE Organização do trabalho}

\begin{tabular}{|c|l|}
\hline Sequência & \multicolumn{1}{|c|}{ UCEs } \\
\hline 1. & $\begin{array}{l}\text { “... você tem que racionalizar o seu tempo de serviço, porque você recebe uma carga muito grande de } \\
\text { trabalho...” }\end{array}$ \\
\hline 2. & “... acho horrível, eu me sinto num cadeado...” \\
\hline 3. & $\begin{array}{l}\text { “... a empresa que tem o ponto eletrônico, ela tem mais garantia numa demanda trabalhista, porque } \\
\text { ela tem o controle ali, quase que efetivo da jornada que o funcionário realmente cumpriu” }\end{array}$ \\
\hline 4. & $\begin{array}{l}\text { "O banco inteiro e a área de controles internos batendo aqui, e a auditoria em cima da gente, são } \\
\text { ógãos externos que nos cobram... então, vêm de todos os lados...” }\end{array}$ \\
\hline 5. & “... então, há uma compreensão também por parte dos gerentes... nessa questão” \\
\hline
\end{tabular}

A análise das UCEs desse núcleo indica abordagens prevalecentes nas temáticas flexibilidade gerencial e controle do trabalho: 
- Flexibilidade das gerências: as verbalizações revelam a existência de grande demanda de serviços, mas indicam reconhecimento de postura flexível das gerências, que possibilita maior autonomia e margem de manobra no cumprimento das tarefas. Essa característica dos gestores pode estar associada à especificidade do ambiente de trabalho estudado, ou seja, setores de uma diretoria de instituição financeira, o que pode não ser verificado em agências bancárias, que compreendem outra natureza de contexto de trabalho (por exemplo, rotinas de atendimento a clientes externos).

- Controle do trabalho: as inovações tecnológicas e organizacionais são vistas pelos entrevistados como elementos que contribuem para o recrudescimento do controle do trabalho. As abordagens focam o acompanhamento interno e externo em relação ao nível de conformidade atingido na realização das atividades na comparação com padrões esperados (prazos, qualidade, correção etc.), e a sistemática de controle da jornada de trabalho por meio do dispositivo ponto eletrônico. As manifestações dos entrevistados demonstram a percepção da importância desse dispositivo para o interesse corporativo (instrumento de gestão da jornada visando a garantias no âmbito da Justiça do Trabalho), mas evidenciam insatisfação com as limitações por ele impostas. Os relatos indicam controle excessivo imposto por essa ferramenta quanto a horários de chegada e saída do trabalho e nos intervalos de almoço. A preocupação em cumprir os prazos impostos pelo ponto eletrônico foi identificada como fonte de estresse entre os trabalhadores, uma vez que promove interferências importantes em sua vida pessoal.

De acordo com Ferreira (2008b), entre as medidas julgadas eficazes para aprimorar a organização do trabalho estão: a) a margem de manobra com vistas à auto-organização; b) a flexibilidade para gestão de horários de trabalho; e c) a postura de escuta da hierarquia em relação às sugestões dos trabalhadores. Ainda segundo Ferreira (2008a), o modelo de gestão do trabalho potencializa a ocorrência de mal-estar em trabalhadores e coloca em risco a eficiência e a eficácia duradouras do processo de trabalho quando, entre outros fatores, impõe controle temporal por parte de chefias, clientes, colegas e, principalmente, de máquinas. Na visão de Queiroz (2003), na estratégia de implementação de novas tecnologias também deve ser considerada a transformação nas relações de autoridade e nos mecanismos de controle, possibilitando aos membros da organização mais autonomia e responsabilidade por suas atividades, o que resulta em maior flexibilidade e eficiência organizacional.

O Quadro 3 apresenta UCEs relacionadas ao NTE Condições de trabalho: usabilidade e custo humano.

Quadro 3: NTE Condições de trabalho: usabilidade e custo humano

\begin{tabular}{|c|l|}
\hline Sequência & \multicolumn{1}{c|}{ UCEs } \\
\hline 1. & $\begin{array}{l}\text { “... você tem que ter o preparo físico e bom, porque senão você carrega toda a tensão aqui e você } \\
\text { digita e você sente dor” }\end{array}$ \\
\hline 2. & “... usar um sistema desses é muito complicado! É muito demorado...” \\
\hline 3. & $\begin{array}{l}\text { “... quando começou a implantar o Office... ele não deu o suporte necessário digamos, ele implantou, } \\
\text { e você usa...” }\end{array}$ \\
\hline 4. & $\begin{array}{l}\text { "... se ela não ficar bem sentada, os braços e cotovelos, não sei se com máquina de escrever, acho que } \\
\text { não tinha esse problema...” }\end{array}$ \\
\hline 5. & "... e o Office mesmo eu procurei por fora, não teve uma especificidade lógica pra ele” \\
\hline 6. & "Hoje... com os programas, com os aplicativos, com a internet, aí, com certeza... melhorou, e muito” \\
\hline
\end{tabular}

A análise das UCEs desse núcleo indica predominância de referências ao custo humano do trabalho e ao treinamento para uso de artefatos tecnológicos: 
- Custo humano do trabalho: o custo físico é relacionado pelos entrevistados à tensão postural na realização das atividades com equipamentos de informática. As verbalizações guardam consonância com estudos de Abrahão e Pinho (2002), que apontam consequências à saúde de trabalhadores em função da informatização, como a fadiga geral, decorrente de dores cervicais. Sob essa perspectiva, relatos de Robertson, Amick III, DeRango, Rooney, Bazzani, Harrist et al. (2009) apontam uma variedade de fatores que contribuem para o desconforto do sistema musculoesquelético, entre os quais destacam a maior quantidade de horas de trabalho em frente ao computador e a falta de recursos ergonômicos nas estações de trabalho. $\mathrm{O}$ custo cognitivo é associado à necessidade de assimilação do funcionamento das ferramentas eletrônicas, tendo em vista as iniciativas frequentes da organização na introdução de novos aplicativos; e às estratégias operatórias utilizadas pelos trabalhadores em relação às limitações desses recursos. Segundo Weill-Fassina (1990), em tempos nos quais as novas tecnologias estão cada vez mais presentes no cenário produtivo, a análise dos aspectos cognitivos do trabalho, do ponto de vista da Ergonomia, parece ser um procedimento prévio indispensável à concepção dos dispositivos e de ajudas que forneçam aos operadores meios para reflexão confiável e para decisão sobre quais ações executar.

- Treinamento em informática: as entrevistas mostraram percepções diferenciadas em relação às oportunidades de treinamento com os aplicativos eletrônicos. Verificaram-se relatos que indicam a insuficiente oferta desse tipo de treinamento pela organização, levando funcionários a buscar capacitação fora do ambiente corporativo, e situações em que são percebidas formas de cooperação entre colegas de trabalho visando à superação das lacunas de treinamento. Ferreira (2008b) destaca a valorização da interação entre colegas, caracterizando a predominância do trabalho coletivo e da participação como um traço das relações sociais de trabalho. Essas ações, tanto a busca por capacitação externa como as ações colaborativas entre colegas de trabalho, ilustram as estratégias operatórias implementadas pelos trabalhadores, na busca pela redução da distância entre o trabalho prescrito, que prevê equipamentos utilizados em sua plenitude pelos trabalhadores, e a situação real, que retrata carência de treinamento no uso das ferramentas.

O Quadro 4 apresenta UCEs relacionadas ao NTE Sobrecarga informacional.

\section{Quadro 4: NTE Sobrecarga informacional}

\begin{tabular}{|c|l|}
\hline Sequência & \\
\hline 1. & “... confraternização, correntes, vêm de todas as espécies... eu simplesmente já estou deletando...” \\
\hline 2. & $\begin{array}{l}\text { "Não olho, só quando eu volto, aí tem quatrocentas e tantas mensagens lá; taí uma coisa } \\
\text { interessante, devia ser bloqueado...” }\end{array}$ \\
\hline 3. & $\begin{array}{l}\text { "Se você passa três, quatro dias, aí você tem lá já cem mensagens entre as que são spam e as que } \\
\text { possivelmente tem interesse em saber" }\end{array}$ \\
\hline 4. & $\begin{array}{l}\text { "E há um outro tipo de mensagem... que me aborrece bastante... duas pessoas estão tratando a } \\
\text { respeito de um processo que não tem nada a ver comigo, mas uma delas manda com cópia pra mim” }\end{array}$ \\
\hline 5. & $\begin{array}{l}\text { “... eu leio as mais importantes... e as outras eu vou deixando ali, se der eu leio, senão, eu vou } \\
\text { deletando, se você não selecionar, você passa o dia todo lendo mensagens" }\end{array}$ \\
\hline 6. & $\begin{array}{l}\text { “... então eu leio, às vezes, mensagens imensas, pra descobrir que aquilo não tem absolutamente nada } \\
\text { a ver comigo... você é muito mais onerado com essas mensagens que nem deveriam chegar" }\end{array}$ \\
\hline 7. & "... assunto corporativo, você tem que ler... Faço pelo menos uma leitura dinâmica...” \\
\hline
\end{tabular}

A análise das verbalizações desse núcleo indica predominância de relatos com enfoque no uso inadequado da forma de comunicação via mensagens eletrônicas (e-mails):

- Encaminhamento indevido de e-mails: segundo relatos dos entrevistados, os e-mails indevidos podem ter origem pessoal, corporativa, comercial ou figurar entre os chamados spams 
(mensagens não solicitadas). Os e-mails de origem pessoal, geralmente encaminhados por colegas de trabalho, da ativa ou aposentados, são de natureza diversificada e geralmente veiculam, além de mensagens relacionadas a trabalho, textos motivacionais, gravuras de entretenimento, frases de final de semana e as chamadas "correntes", que visam a associar a realização de desejos ao ato de reenviar a mensagem recebida. E-mails corporativos também foram considerados indevidos pelos entrevistados quando não mantinham ligação com seu trabalho ou são enviados em duplicidade. As motivações para o envio desses e-mails foram associadas ao desinteresse, por parte do remetente, em conhecer o correto destinatário da mensagem e à prática do envio indiscriminado de cópias de mensagens. As mensagens comerciais são provenientes de fontes externas e veiculam oferta de produtos e/ou serviços diversos, desde bens de uso doméstico até cursos de línguas estrangeiras e treinamento corporativo. A estratégia citada pelos entrevistados para o tratamento às mensagens indevidas foi a eliminação daquelas consideradas inúteis e/ou suspeitas, mediante critérios que podem se basear, preliminarmente, no nome do remetente ou no título da mensagem e, caso necessário, no seu conteúdo.

- Mensagens durante ausências prolongadas: uma segunda situação relatada pelos entrevistados, que retrata a sobrecarga de mensagens eletrônicas, trata da questão das ausências prolongadas, como no caso de férias, quando não há interrupção do envio de e-mails para suas caixas postais pessoais corporativas.

Nas duas situações apresentadas, verificou-se impacto em todas as dimensões do custo humano do trabalho. O custo emocional pode ser exemplificado: a) quando do sentimento de insegurança ao se eliminar sumariamente e-mails antes de uma análise criteriosa, que demandaria tempo adicional durante o período de trabalho; b) em casos de aborrecimentos com colegas pelo envio indiscriminado de mensagens; e c) pela constatação do tempo perdido com o tratamento de mensagens inúteis, comprometendo a realização de outras atividades. Os custos físico e cognitivo foram percebidos: a) nos relatos sobre ações confirmatórias da pertinência das mensagens recebidas por meio de telefonemas ou deslocamentos pessoais; b) na análise de cada mensagem ou título, especialmente quando acumuladas em função de ausências prolongadas; e c) na leitura de mensagens extensas na busca por possível conteúdo de interesse do funcionário.

A sobrecarga informacional, motivada pelo excesso de e-mails, e o insucesso no bloqueio de mensagens indesejáveis, presentes no relato dos entrevistados, foram verificados nos estudos de Olson e Olson (2003), que destacam a necessidade de intervenção humana substancial para a eficácia na limitação do excesso de mensagens.

O Quadro 5 apresenta UCEs relacionadas ao NTE Aumento da responsabilidade e segurança.

\section{Quadro 5: NTE Aumento da responsabilidade e segurança}

\begin{tabular}{|c|c|}
\hline Sequência & UCEs \\
\hline 1. & $\begin{array}{l}\text { "... sim, tanto eu posso levar... na sala dela, como se ela estiver em reunião, eu posso mandar para o e- } \\
\text { mail dela" }\end{array}$ \\
\hline 2. & $\begin{array}{l}\text { “... então, depois que você manda um e-mail, não é como uma carta que você pode pedir de volta } \\
\text { para fazer uma mudança, aquilo ali já está disseminado no banco" }\end{array}$ \\
\hline 3. & “... a responsabilidade ficou realmente um pouco maior, sim, com certeza" \\
\hline 4. & “... você tem que dar uma resposta... não pode dizer que não vai responder. Está registrado” \\
\hline 5. & $\begin{array}{l}\text { “... não te custava nada levantar e ir até a mesa da pessoa e falar: fulano... mas, você faz questão de } \\
\text { registrar aquilo e assinar" }\end{array}$ \\
\hline 6. & "... porque ela me manda uma consulta, e tudo tem que estar registrado..." \\
\hline
\end{tabular}


A análise dos relatos desse núcleo indica a predominância de referências às relações socioprofissionais e ao aumento da responsabilização no trabalho:

- Relações sociais no trabalho e a tarefa a ser executada: os recursos da tecnologia da informação, em especial os e-mails, foram citados pelos entrevistados como agentes que ora aproximam, ora distanciam as pessoas no trabalho. Há casos em que se prefere efetuar deslocamentos para priorizar um contato pessoal e outros em que há troca de e-mails entre colegas que trabalham lado a lado. A opção geralmente ocorre em função da natureza do trabalho em execução; situações em que se percebe a necessidade de se registrar um contato, um parecer ou uma autorização, visando a resguardar interesses, direcionam a opção para o registro formal do contato, via e-mail. Essa situação é confirmada nos estudos de Bellotti et al. (2002), que citam e-mails sendo utilizados com a finalidade de atribuir responsabilidades a pessoas e para registrar decisões tomadas. Em outros relatos, os e-mails foram apontados pelos entrevistados como importante ferramenta na quebra de barreiras hierárquicas, muito comuns na era da préinformatização. Os exemplos trazem situações em que os funcionários podem efetuar contatos com seus superiores por meio de e-mails, mesmo quando estão ausentes do ambiente de trabalho, e também com níveis de chefia acima de seus superiores. Essa situação é verificada em relatos de Orlikowski (2000), que cita esse uso do e-mail na diminuição da hierarquia da estrutura de comunicação e ressalta que isso possibilita o desvio dos canais convencionais para a interação com membros da alta administração.

- Responsabilização agregada à tecnologia: na comparação com períodos anteriores à chamada "era da informação", houve relatos de entrevistados em que atribuem à tecnologia maior poder de responsabilização das pessoas pelo trabalho efetuado. A formalização imputada por dispositivos como e-mails e sistemas que registram os acessos, com data e horário, inclusive duração das sessões nas quais ocorrem as conexões, concretizam vínculos entre o trabalho realizado e seus responsáveis. Isso acarreta a esses executores maior custo cognitivo, na dedicação maior quando do registro das informações; e afetivo, uma vez que seu estado emocional é afetado pela possibilidade de responsabilização por erros durante a realização das atividades. O poder disseminador dos e-mails, que expõe, de forma irreversível, posições, decisões e críticas de seus remetentes a inúmeros "juízes", também foi considerado pelos entrevistados fator importante que contribui para o aumento do custo emocional no trabalho.

\section{Conclusão}

Após a análise dos dados e discussão dos resultados com base na literatura revisada e ao referencial teórico adotado, procedeu-se ao resgate das questões de pesquisas, bem como de suas correspondentes hipóteses, com vistas à verificação da ocorrência ou não de sua confirmação.

Em relação à questão de pesquisa "como os trabalhadores percebem as inovações tecnológicas e organizacionais no seu trabalho?", para a qual foi apresentada a hipótese "os trabalhadores percebem as inovações como algo necessário, que provê condições de racionalizar sua atividade, mas que demanda empenho adicional no trabalho", verificou-se que os entrevistados reconhecem a importância das inovações tecnológicas, quando citam diversas de suas funcionalidades que facilitam a realização do trabalho, mas suscitam situações que evidenciam o aumento do custo humano do trabalho.

Sobre a questão "como se caracterizam as novas exigências do trabalho, acarretadas pelas inovações tecnológicas e organizacionais, na visão dos trabalhadores?", que teve como 
hipótese "as novas exigências são entendidas como fatores associados às inovações tecnológicas, que demandam grande conjunto de esforços cognitivos, com possibilidades de repercussão no aspecto físico dos trabalhadores", percebeu-se a associação, pelos entrevistados, entre as inovações tecnológicas e organizacionais e repercussões no custo humano do trabalho, as quais não se limitaram ao custo cognitivo e físico, mas se referiram também ao custo afetivo dos trabalhadores.

Com referência à questão "quais são as formas pelas quais as inovações interferem na implementação de estratégias operatórias pelos trabalhadores, na busca pela eficiência com preservação de sua segurança e saúde?", para a qual foi apresentada a hipótese "as inovações, concebidas sem a participação dos usuários, tornam mais complexas suas ações no trabalho e limitam o desenvolvimento de estratégias operatórias na realização de suas atividades", verificou-se, na visão dos entrevistados, a importância do conhecimento, por parte dos projetistas, da realidade de trabalho daqueles que utilizam a tecnologia, o que foi reforçado com relatos de dificuldades no uso de artefatos tecnológicos de cuja concepção não participaram, como, por exemplo, o dispositivo de ponto eletrônico.

Em relação à questão "quais são os efeitos das novas exigências do trabalho na qualidade de vida no trabalho, percebidos pelos trabalhadores?”, para a qual foi apresentada a hipótese "as novas exigências do trabalho têm o potencial de interferir negativamente na eficiência e na saúde dos trabalhadores, comprometendo sua qualidade de vida no trabalho", verificou-se, no relato dos entrevistados, referências à tensão no trabalho, sentimentos de dor e a problemas com postura, o que denota efeitos das exigências do trabalho na saúde dos trabalhadores. Os impactos negativos na eficiência e eficácia do trabalho, apesar dos relatos de avanços da tecnologia e seus reflexos positivos na produtividade, também foram confirmados nas verbalizações dos entrevistados.

\section{Recomendações específicas para o contexto de trabalho estudado}

Considerando que a pesquisa se inspirou em pressupostos da Ergonomia da Atividade, o que agrega ao estudo o interesse pela aplicação de seus resultados, foram apresentadas recomendações de ordem prática para as questões consideradas de maior relevância.

Em relação à intensificação do trabalho, em que pese o caráter global do fenômeno, entendeu-se que há um nível possível de intervenção local, de forma a amenizar o ritmo intenso de trabalho, relatado nas entrevistas. Assim, foi sugerido à organização estudada: a) adotar práticas de incentivo à realização de pausas entre as atividades ao longo de toda a jornada de trabalho; b) apoiar ações colaborativas entre funcionários, visando à otimização de recursos e conhecimentos; e c) adotar postura receptiva a sugestões para a melhoria da organização do trabalho, inclusive quanto à carga de trabalho e à gestão do cumprimento de metas. Aos gestores também foi recomendado o acompanhamento próximo das atividades dos funcionários, com vistas à implementação de intervenções, quando necessárias, visando à eliminação ou à redução de fatores geradores de mal-estar no trabalho.

Quanto ao conforto no trabalho, foi recomendada a realização de Análise Ergonômica do Trabalho com o objetivo de verificar, além dos problemas posturais relatados nas entrevistas, outras questões relacionadas ao conforto físico, como a interação com mobiliário, equipamentos e ambiente, e à organização do trabalho.

Com o objetivo de diminuir as dificuldades na utilização de softwares livres, foi recomendado o fornecimento de módulos de treinamento para esses aplicativos, com ênfase nas diferenças em relação aos softwares comerciais. Foi sugerida, também, a disponibilização de cursos com abordagem no uso de softwares diversos, incluindo módulos digitais para utilização nas estações de trabalho dos próprios funcionários e disponibilização de serviço de help desk (suporte técnico) para o tratamento de dúvidas. 
Em relação à sobrecarga informacional, com vistas à redução da quantidade de e-mails indevidos, foram apresentadas as seguintes recomendações, destinadas à organização pesquisada: a) implantar sistema de inibição do envio de e-mails a funcionários em férias, licença-saúde ou em outra situação de ausência prolongada, com redirecionamento da mensagem a caixas postais corporativas, para tratamento por outros funcionários na ativa. Ao sistema caberia informar aos remetentes, de forma automática, a condição de ausente do destinatário e o novo destino do e-mail; b) desenvolver, com o corpo funcional, política de orientação acerca do uso racional do correio eletrônico, de forma a evitar o envio de cópias indevidas ou desnecessárias e priorizar o encaminhamento de mensagens às caixas postais corporativas, reservando o uso do e-mail pessoal corporativo às situações especiais. Foi sugerida também a adoção de política de incentivo ao uso de textos concisos, inclusive com limitação na quantidade de caracteres, visando à diminuição do tempo gasto com informações desnecessárias.

Em relação às limitações impostas pelo ponto eletrônico, relatadas nas entrevistas, foi sugerida a realização de pesquisa com funcionários sujeitos ao uso do sistema, em parceria com as gerências, com vistas à obtenção de insumos que possam torná-lo mais flexível, permitindo ao usuário maior margem de manobra e autonomia, sem que isso provoque a perda de controle pelo empregador do cumprimento da jornada de trabalho.

\section{Relevância da pesquisa e agenda para trabalhos futuros}

No âmbito social, considerou-se que o estudo presta sua contribuição quando dá visibilidade à questão tratada na pesquisa, o que possibilita o surgimento de discussões e iniciativas que visem à melhoria da qualidade de vida no trabalho em diversas atividades profissionais.

No âmbito corporativo, percebeu-se que o estudo possibilita à organização analisada melhor entendimento das questões tratadas na pesquisa e que guardam relação direta com seu processo produtivo. Dessa forma, os resultados e recomendações apresentados podem se constituir em insumos para a racionalização de processos, tanto administrativos quanto operacionais, com vistas à melhoria da qualidade de vida no trabalho e da eficiência corporativa.

De acordo com reflexão de Deslandes (2007), todo conhecimento científico tem um caráter provisório, uma vez que a realidade social se modifica; e inacessível em relação à totalidade do objeto, dada a imprecisão das ideias em relação à realidade. Assim, o trabalho de pesquisa ora relatado, que apresentou limitações, a exemplo do uso parcial dos pressupostos da Análise Ergonômica do Trabalho, vislumbra possibilidades de novos estudos, utilizando como base seus achados, que possam buscar conhecer o foco de interesse de um universo maior de trabalhadores, estejam eles em instituições financeiras ou em qualquer outra organização que se enquadre no contexto de trabalho pesquisado.

\section{Referências}

Abrahão, J. I. \& Pinho, D. L. M. (2002). As transformações do trabalho e desafios teórico-metodológicos da ergonomia. Estudos de Psicologia, 7 (especial), 45-52.

Antunes, R. (2007). Prefácio à sétima edição. In Adeus ao trabalho? Ensaio sobre as metamorfoses e a centralidade do mundo do trabalho (pp. 9-16). São Paulo: Cortez.

Bauer, M. W. \& Gaskell, G. (2002). Pesquisa qualitativa com texto, imagem e som: um manual prático (5ª ed.). Petrópolis, RJ: Vozes. 
Bellotti, V., Ducheneaut, N., Howard, M., Neuwirth C. \& Smith, I. (2002). Innovation in extremis: evolving an application for the critical work of email and information management. In ACM Conference on Designing Interactive Systems (DIS 2002) (pp. 181-192). London: ACM.

Dal Rosso, S. (2008). Intensificação do trabalho: teoria e método. In S. Dal Rosso \& J. A. A. S. Fortes (Org.), Condições de trabalho no limiar do século XXI (pp. 21-36). Brasília, DF: Época.

Daniellou, F. (2004). Questões epistemológicas acerca da ergonomia. In A ergonomia em busca de seus princípios: debates epistemológicos (pp. 1-18). São Paulo: Edgard Blücher.

Deslandes, S. F. (2007). O projeto de pesquisa como exercício científico e artesanato intel ectual. In M. C. S. Minayo (Org.), Pesquisa social: teoria, método e criatividade (pp. 31-60). Petrópolis, RJ: Vozes.

Egbu, C. O. \& Botterill, K. (2002). Information technologies for knowledge management: their usage and effectiveness. ITcon, 7 (especial), 125-136.

Ferreira, M. C. (2003). O sujeito forja o ambiente, o ambiente "forja" o sujeito: mediação indivíduo-ambiente em ergonomia da atividade. In M. C. Ferreira \& S. Dal Rosso (Orgs.), A regulação social do trabalho (pp. 21. 46). Brasília, DF: Paralelo 15.

Ferreira, M. C. (2004). Bem-estar: equilíbrio entre a cultura do trabalho prescrito e a cultura do trabalho real. In Álvaro Tamaio (Org.), Cultura organizacional e saúde (pp. 127-157). São Paulo: Artmed.

Ferreira, M. C. (2006a). Competência profissional do bem-estar. Artigo disponível na Internet: www.secom.unb.br/artigos/at1106-04.htm [4 fevereiro 2009].

Ferreira, M. C. (2006b). Qualidade de vida no trabalho. In Dicionário de trabalho e tecnologia (vol. 1, pp. 219-222). Porto Alegre: UFRGS.

Ferreira, M. C. (2008a). A ergonomia da atividade se interessa pela qualidade de vida no trabalho? Reflexões empíricas e teóricas. Cadernos de Psicologia Social do Trabalho, 11 (1), 83-99.

Ferreira, M. C. (2008b). O que pensam os trabalhadores franceses sobre as novas exigências do trabalho? In S. D. Rosso \& J. A. A. S. Fortes (Org.), Condições de trabalho no limiar do século XXI (pp. 173-188). Brasília, DF: Época.

Ferreira, M. C. (2009, 14 de fevereiro). Embrutecimentopatia. Correio Braziliense, Caderno Opinião, 27.

Ferreira, M. C. \& Mendes, A. M. (2003). Trabalho e riscos de adoecimento: o caso dos auditores-fiscais da previdência social brasileira. Brasília, DF: Ler, Pensar, Agir.

Friedmann, G. (1952). Technological change and human relations. The British Journal of Sociology, 3 (2), 95-116.

Grandjean, E. (1998). Prefácio. In Manual de ergonomia: adaptando o trabalho ao homem. Porto Alegre: Artmed.

Guérin, F., Laville, A., Daniellou, F., Duraffourg, J. \& Kerguelen, A. (2001). Compreender o trabalho para transformálo: a prática da ergonomia. São Paulo: Edgard Blücher.

Ho, J. T. S. (1997). Corporate wellness programs in Singapore: effect on stress, satisfaction and absenteeism. Journal of Managerial Psychology, 12 (3), 177-189.

Howell, W. C. (1993). Engineering psychology in a changing world. Annual Reviews: Psychology, 44, 231-263.

Iida, I. (2005). Métodos e técnicas em ergonomia. In Edgard Blücher (Ed.), Ergonomia: projeto e produção (pp. 60 62). São Paulo: Edgard Blücher.

Kaplan, R. S. \& Norton, D. P. (1996). Measurement and management in the information age. In The balanced scorecard: translating strategy into action (pp. 1-20). Boston, MA: Harvard Business School Press.

Laville, A. (1977). A ergonomia no mundo. In Ergonomia (pp. 1-10). São Paulo: EPU.

Leite, M. P. (1994). Modernização tecnológica e relações de trabalho. In C. Ferretti, D. Zibas, F. Madeira \& M. L. Franco (Orgs.), Tecnologias, trabalho e educação: um debate multidisciplinar (pp. 36-53). Petrópolis, RJ: Vozes.

Marmaras, N. \& Pavard, B. (1999). Problem-driven approach to the design of information technology systems supporting complex cognitive tasks. Cognition, Technology Eु Work, 1, 222-236.

May, B. E., Lau, R. S. M. \& Johnson, S. K. (1999). A longitudinal study of quality of work life and business performance. Business Review, 58 (2), 1-7.

McCampbell, A. S., Clare, L. M. \& Gitters, S. H. (1999). Knowledge management: the new challenge for the 21st century. Journal of Knowledge Management, 3 (3), 172-179.

Nathanael, D. \& Marmaras, N. (2001). Ecological design of informatics systems: a new paradigm to achieve usability and effectiveness. In N. Avouris \& N. Fakotakis (Eds.), Advances in human-computer interaction (vol. 1, pp. 65-70). Pátras, Grécia: Typorama.

Nathanael, D., Marmaras, N. \& Papantoniou, B. (2003). Designing for proficient users: drawing from the realities of practice. In J. Jacko \& C. Stephanidis (Eds.), Human-computer interaction theory and practice (vol. 1, pp. 183-187). Zografou, Grécia: Constantine Stephanidis.

Olson, G. M. \& Olson, J. S. (2003). Human-computer interaction: psychological aspects of the human use of computing. Annual Reviews: Psychology, 54, 491-516.

Orlikowski, W. J. (2000). Using technology and constituting structures: a practice lens for studying technology in organizations. Organization Science, 11 (4), 404-428.

Peduzzi, M. (2002). Mudanças tecnológicas e seu impacto no processo de trabalho em saúde. Trabalho, Educação e Saúde, 1 (1), 75-91.

Queiroz, A. C. S. (2003). Novas tecnologias e inovação organizacional. Tese de Doutorado, Fundação Getulio Vargas, São Paulo. 
Robertson, M., Amick III, B.C., DeRango, K., Rooney, T., Bazzani, L., Harrist, R. et al. (2009). The effects of an office ergonomics training and chair intervention on worker knowledge, behavior and musculoskeletal risk. Applied Ergonomics, 40, 124-135.

Royuela, V., López-Tamayo, J. \& Suriñach, J. (2007). The institutional vs. the academic definition of the quality of work life. What is the focus of the European Commision? Research Institute of Applied Economics, 13, 1-15.

Society for Human Resource Management. (2007). Communication and technology. In K. Scanlan (Ed.), Workplace communication series, part III. Artigo disponível na Internet: learncma-intl.com/ads/March08/Human \%20Resources.pdf [14 fevereiro 2009].

Van de Ven, A. H. (1986). Central problems in the management of innovation. Management Science, 32 (5), 590. 607.

Weill-Fassina, A. (1990). Les analyses du travail. Enjeux et formes. Cereq, 54, 193-198.

Wisner, A. (1994a). A metodologia na ergonomia: ontem e hoje. In Fundacentro (Ed.), A inteligência no trabalho: textos selecionados de ergonomia (pp. 93-98). São Paulo: Fundacentro.

Wisner, A. (1994b). Organização do trabalho, carga mental e sofrimento psíquico. In Fundacentro (Ed.), A inteligência no trabalho: textos selecionados de ergonomia (pp. 11-20). São Paulo: Fundacentro.

\section{Endereço para correspondência}

brusiquese@uol.com.br, mcesar@unb.br

Recebido em 20/09/2010

Revisado em 30/05/2011

Aprovado em 30/06/2011 